\section{(6) OPEN ACCESS}

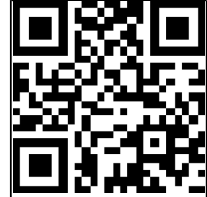

Open Access Scan to access mor free content

- Additional material is published online only. To view please visit the journal online (http://dx.doi.org/10.1136/ heartjnl-2013-304958).

${ }^{1}$ Departments of Cardiology, Boston Children's Hospital and Department of Pediatrics, Harvard Medical School, Boston, Massachusetts, USA ${ }^{2}$ NIHR Cardiovascular Biomedical Research Unit, Royal Brompton and Harefield NHS Foundation Trust, National Heart and Lung Institute, Imperial College, London, UK

${ }^{3}$ Department of Cardiology, Academic Medical Centre, Amsterdam, The Netherlands ${ }^{4}$ Division of Cardiology, University of Toronto, Peter Munk Cardiac Centre, Toronto, Ontario, Canada

\section{Correspondence to} Dr Anne Marie Valente, Department of Cardiology, Boston Children's Hospital, 300 Longwood Avenue, Boston, MA 02115, UK anne.valente@cardio.chboston. org

Received 13 September 2013 Revised 26 September 2013 Accepted 27 September 2013 Published Online First 31 October 2013

\section{SLinked}

- http://dx.doi.org/10.1136/ heartjnl-2013-305011

To cite: Valente AM, Gauvreau K, Egidy Assenza $G$, et al. Heart 2014;100:247-253.

\title{
Contemporary predictors of death and sustained ventricular tachycardia in patients with repaired tetralogy of Fallot enrolled in the INDICATOR cohort
}

\author{
Anne Marie Valente, ${ }^{1}$ Kimberlee Gauvreau, ${ }^{1}$ Gabriele Egidy Assenza, ${ }^{1}$ \\ Sonya V Babu-Narayan, ${ }^{2}$ Jenna Schreier, ${ }^{1}$ Michael A Gatzoulis, ${ }^{2}$ Maarten Groenink, ${ }^{3}$ \\ Ryo Inuzuka, ${ }^{2}$ Philip J Kilner, ${ }^{2}$ Zeliha Koyak, ${ }^{3}$ Michael J Landzberg, ${ }_{1}^{1}$ Barbara Mulder, ${ }^{3}$ \\ Andrew J Powell, ${ }^{1}$ Rachel Wald, ${ }^{4}$ Tal Geva ${ }^{1}$
}

\section{ABSTRACT \\ Objective Patients with repaired tetralogy of Fallot (TOF) experience increased rates of mortality and morbidity in adulthood. This study was designed to identify risk factors for death and ventricular tachycardia (VT) in a large contemporary cohort of patients with repaired TOF.}

Methods Subjects with repaired TOF from four large congenital heart centres in the USA, Canada and Europe were enrolled. Clinical, ECG, exercise, cardiac magnetic resonance (CMR) and outcome data were analysed.

Results Of the 873 patients (median age 24.4 years), $32(3.7 \%)$ reached the primary outcome (28 deaths, 4 sustained VT; median age at outcome 38 years; median time from CMR to outcome 1.9 years). Cox proportionalhazards regression identified RV mass-to-volume ratio $\geq 0.3 \mathrm{~g} / \mathrm{mL}$ (HR, 5.04; $95 \% \mathrm{Cl} 2.3$ to $11.0 ; p<0.001)$, LV EF z score $<-2.0$ (HR, 3.34; $95 \%$ Cl 1.59 to 7.01 ; $\mathrm{p}=0.001)$, and history of atrial tachyarrhythmia (HR, $3.65 ; 95 \% \mathrm{Cl} 1.75$ to $7.62 ; p=0.001$ ) as outcome predictors. RV dysfunction was predictive of the outcome similar to LV dysfunction. In subgroup analysis of 315 subjects with echocardiographic assessment of RV systolic pressure, higher pressure (HR 1.39; 95\% Cl 1.19 to $1.62 ; p<0.001$ ) was associated with death and sustained VT independent of RV hypertrophy and LV dysfunction.

Conclusions RV hypertrophy, ventricular dysfunction and atrial tachyarrhythmias are predictive of death and sustained VT in adults with repaired TOF. These findings may inform risk stratification and the design of future therapeutic trials.

\section{INTRODUCTION}

Despite significant advances in the early management of tetralogy of Fallot (TOF) and 20-year survival rates exceeding 90\%, residual hemodynamic and electrophysiological abnormalities contribute to increasing morbidity and mortality rates beginning in the third decade of life. ${ }^{1-4}$ Since the first reports of sudden death in survivors of TOF repair from 40 years ago, numerous attempts have been made to define risk factors for adverse clinical outcomes. ${ }^{56}$ Most reports, however, suffer from a small sample size of patients predominantly operated in the late 1950 s to the early 1970s when surgical techniques were evolving rapidly. Furthermore, the ability to noninvasively assess RV size and function, which are notably affected by sequelae of TOF surgery, was limited and imprecise. ${ }^{7}$ A previous multicentre cohort study identified QRS duration $\geq 180 \mathrm{~ms}$ as a predictor of death and clinical arrhythmia in patients with repaired TOF. ${ }^{8}$ However, as with other studies from that era, assessment of the RV was imprecise. More recently, the advent of cardiovascular magnetic resonance (CMR) has allowed accurate and reproducible noninvasive measurements of biventricular size and function and quantification of valvular regurgitation. ${ }^{9-11}$ Several single-centre studies have indicated that severe RV dilatation and RV and/or LV dysfunction measured by CMR are important risk factors for adverse clinical outcomes, superseding the importance of QRS prolongation as a predictor of outcome. ${ }^{12} 13$ These studies, similarly, were hampered by small sample sizes and paucity of hard outcomes.

To overcome these limitations and to determine risk factors for death and sustained ventricular tachycardia (VT) in a large contemporary cohort of TOF repair survivors, we have established the International Multicenter TOF Registry (INDICATOR). ${ }^{14}$ The goals of this registry, which enrolled contemporarily managed patients from four large congenital heart centres in the USA, Canada and Europe, were to allow risk stratification based on clinical, ECG, exercise and CMR data and to explore whether these risk factors vary according to type of repair.

\section{METHODS}

\section{Patients}

A detailed description of the methodology of the INDICATOR registry, including recruitment protocol, inclusion and exclusion criteria, data collection and data analysis in the core laboratory has been published. ${ }^{14}$ Briefly, participating centres identified patients fulfilling the following inclusion criteria: (1) repaired TOF; (2) CMR completed between 1997 and 2010; (3) 12-lead ECG within 1 year from CMR; and (4) clinical follow-up $\geq 1$ year or occurrence of a primary outcome. Patients with CMR data that were incomplete or not suitable for quantitative assessment by the CMR core laboratory were excluded. Each participating centre received Institutional Review or Ethical Board approval. 


\section{Data collection}

De-identified data were sent to the data coordinating centre, which included a data repository, CMR core laboratory and a statistical core centre. The registry collected data on patient demographics (date of birth, gender, race), anatomic type of TOF, associated anomalies, surgical and catheter interventions and clinical outcomes. Clinical history and dates of any arrhythmias were recorded, including atrial ablation prior to a documented outcome and pacemaker or defibrillator implantation after CMR.

The following diagnostic studies were sought at the time of enrolment: CMR, ECG, ambulatory 24-h Holter monitor and exercise stress test. One centre also collected Doppler echocardiographic data to quantify RV systolic pressure based on peak velocities of the tricuspid regurgitation jet and RV outflow. The ECG was analysed for heart rate and QRS duration. The 24-h Holter monitor was analysed for atrial arrhythmia (categorised as supraventricular tachycardia, atrial fibrillation or atrial flutter) and for ventricular ectopy (defined as $>100$ premature ventricular contractions, $>20$ couplets or nonsustained VT lasting $<30$ s).

De-identified digital copies of the CMR examinations were sent to the CMR core laboratory for analysis. The technical details of the CMR imaging protocol, analysis methods and quality assurance procedures have been published. ${ }^{10} \quad 14 \quad 15$ Measurements included diastolic and systolic RV and LV volumes, mass and pulmonary regurgitation fraction. Calculations included ventricular stroke volumes and EFs. Measurements were adjusted to body surface area and z scores were calculated.

\section{Outcomes}

The combined primary outcome was defined as all-cause mortality (classified as sudden cardiac death, heart failure-related death, cardiac other or non-cardiac), aborted sudden cardiac death (defined as resuscitated pulseless cardiac event) or sustained VT (lasting $\geq 30 \mathrm{~s}$ or requiring cardioversion). Participating centres updated the data coordinating centre every 6 months regarding new clinical outcomes, including periodic reviews of available national death registries.

\section{Statistical analysis}

Categorical variables were summarised using frequencies and percentages and compared for patients with and without the primary outcome using Fisher's exact test. Continuous variables were summarised using either the mean and SD or median and range; they were compared using the unpaired $t$ test or Wilcoxon rank-sum test. Cox proportional hazards regression was used to evaluate factors associated with time from last CMR until death, aborted sudden cardiac death or sustained VT. Patients who did not experience the primary outcome were censored at the time of last follow-up. Hazard ratios (HR)s are reported with 95\% CIs. Harrell's c-index was used to quantify how well the model discriminates between subjects who experienced the outcome and those who did not. The c-index extends the area under the receiver-operator curve (c-statistic) for binary outcomes to the case of censored survival time data; a value of 0.5 indicates that the model has no ability to predict the outcome, while a value of 1.0 indicates that the model perfectly discriminates between subjects with and without the outcome. Stepwise forward selection was used to fit a multivariable model. Once the factors most strongly associated with the primary outcome were identified, cut points were considered for continuous variables. Nagelkerke's $\mathrm{R}^{2}$ was reported for the final models. This value approximates the amount of variability in the outcome explained by the factors in the model. Analyses were repeated for the subgroups of patients with and without RV-to-pulmonary artery (RV-PA) conduits. In order to evaluate the relationship between RV systolic pressure and outcome, a subgroup analysis was performed for patients in whom RV pressure data were available within 1 year of the CMR. A two-sided $\mathrm{p}$ value of less than 0.05 was considered to indicate statistical significance. Statistical analyses were performed using Stata V.12 (StataCorp, College Station, Texas, USA).

\section{RESULTS}

\section{Study patients}

Of the 1265 subjects screened for enrolment, 873 fulfilled entry criteria, and thus, formed the study cohort. Their demographic, anatomic and surgical characteristics are shown in table 1. Selected laboratory data stratified by outcome are listed in table 2.

Of the 873 cohort patients, 32 experienced the primary outcome of death $(n=28)$ or sustained VT $(n=4)$. Median follow-up from first CMR was 4.2 years (15 days to 12.2 years). Outcomes occurred from 4 days to 9.2 years (median 1.9 years) after baseline evaluation at a median age of 38 years (1.774.6 years). Of the 28 deaths (median age 41.8 years), 4 (14\%) were classified as sudden cardiac death (median age 43 years), 6 $(22 \%)$ as heart failure-related (median age 53.7 years), 4 (14\%) as other cardiac (median age 38.5 years), 9 (32\%) as non-cardiac (median age 44.4 years), and 5 (28\%) as unknown (median age 32 years). The median age at presentation of sustained VT was 29.3 years.

\section{Predictors of outcomes}

Multiple demographic, clinical, ECG, exercise and CMR variables were associated with the outcome on univariable analysis (table 3). Although duration of the QRS complex on ECG was not associated with the outcome when analysed as a continuous variable, QRS duration $\geq 180 \mathrm{~ms}$ was an outcome predictor (HR, 3.17; 95\% CI 1.42 to $7.10 ; \mathrm{p}=0.005$ ). Importantly, compared with a model that includes CMR-measured RV mass-to-volume ratio and $\mathrm{LV} \mathrm{EF}$, the c-index of a model that includes only QRS duration $\geq 180 \mathrm{~ms}$ was significantly lower $(0.85$ vs $0.59, p=0.001)$. Notably, RV end-diastolic volume and $\mathrm{RV} / \mathrm{LV}$ end-diastolic volume ratio were not associated with the outcome whereas RV and LV EF, RV mass index, and RV mass-to-volume ratio were strongly related to death and sustained VT.

The best predictive model for death and sustained VT by multivariable analysis included RV mass-to-volume ratio $\geq 0.3 \mathrm{~g} / \mathrm{mL}$, LV EF z score $<-2.0(<55 \%$ in males and $<54 \%$ in females), and history of atrial tachyarrhythmias (model c-index $0.832 ; \mathrm{R}^{2}$ 0.246; table 4). Using Kaplan-Meier analysis, we found that in patients with none of the above predictors, freedom from the outcome was $98 \%$ at 5 and 10 years. In contrast, freedom from the outcome at 5 and 10 years was $95 \%$ and $86 \%$, respectively, in patients with RV mass-to-volume ratio $\geq 0.3 \mathrm{~g} / \mathrm{mL} ; 86 \%$ and $74 \%$, respectively, in patients with $\mathrm{RV}$ mass-to-volume ratio $\geq 0.3 \mathrm{~g} / \mathrm{mL}$ and LV EF $\mathrm{z}$ score $<-2.0$; and $65 \%$ and $43 \%$, respectively, in patients with all three risk factors (figure 1). Replacement of LV EF z score $<-2.0$ with RV EF z score $<-2.0(<48 \%$ in males and $<50 \%$ in females) resulted in only slight decreases in the model's c-index and $\mathrm{R}^{2}$ values. Finally, we found that the above risk factors were associated with the outcome regardless of the type of death. Specifically, 
Table 1 Demographic, anatomic and surgical characteristics

\begin{tabular}{|c|c|c|c|c|}
\hline Variable & All patients $(\mathrm{N}=873)$ & Outcome (death/VT) (N=32) & No outcome $(\mathrm{N}=841)$ & p Value \\
\hline Median age at repair (years) & $2.9(0-57.2)$ & $5.5(0-40.9)$ & $2.9(0-57.2)$ & 0.08 \\
\hline Median age at last CMR (years) & $24.4(0.2-72.3)$ & $35.3(0.6-72.3)$ & $24.1(0.2-71.6)$ & 0.02 \\
\hline Time from repair to CMR (years) & $21(0-58)$ & $26(0-38)$ & $21(0-58)$ & 0.27 \\
\hline Follow-up time after first CMR (years) & $4.2(0.04-12.2)$ & $2.8(0.04-11.2)$ & $4.2(0.09-12.2)$ & 0.26 \\
\hline Gender, male & $479(55 \%)$ & $20(63 \%)$ & $459(55 \%)$ & 0.47 \\
\hline Body surface area $\left(\mathrm{m}^{2}\right)$ & $1.7 \pm 0.4$ & $1.7 \pm 0.5$ & $1.7 \pm 0.4$ & 0.75 \\
\hline Diagnosis & & & & 0.001 \\
\hline Tetralogy of Fallot, pulmonary stenosis & $725(83 \%)$ & $19(59 \%)$ & $706(84 \%)$ & \\
\hline Tetralogy of Fallot, pulmonary atresia & $131(15 \%)$ & $13(41 \%)$ & $118(14 \%)$ & \\
\hline Tetralogy of Fallot, AV canal & $17(2 \%)$ & $0(0 \%)$ & $17(2 \%)$ & \\
\hline Additional cardiovascular anomaly & $323(37 \%)$ & $12(38 \%)$ & $311(37 \%)$ & 1.00 \\
\hline Comorbidities & $197(23 \%)$ & $11(34 \%)$ & $186(22 \%)$ & 0.13 \\
\hline Associated genetic disorder & $87(10 \%)$ & $5(16 \%)$ & $82(10 \%)$ & 0.24 \\
\hline Prior palliative shunt & $314(36 \%)$ & $19(59 \%)$ & $295(35 \%)$ & 0.008 \\
\hline Type of repair & & & & $<0.001$ \\
\hline Transannular patch & $442(51 \%)$ & $7(22 \%)$ & $435(52 \%)$ & \\
\hline RV-to-PA conduit & $119(14 \%)$ & $13(41 \%)$ & $106(13 \%)$ & \\
\hline Non-transannular patch & $136(16 \%)$ & $5(16 \%)$ & $131(16 \%)$ & \\
\hline Infundibular resection and pulmonary valvotomy & $51(6 \%)$ & $1(3 \%)$ & $50(6 \%)$ & \\
\hline Infundibular resection alone & $29(3 \%)$ & $1(3 \%)$ & $28(3 \%)$ & \\
\hline Pulmonary valvotomy alone & $28(3 \%)$ & $2(6 \%)$ & $26(3 \%)$ & \\
\hline Other & $68(8 \%)$ & $3(9 \%)$ & $65(8 \%)$ & \\
\hline Subsequent revision of repair & $261(30 \%)$ & $12(38 \%)$ & $249(30 \%)$ & 0.33 \\
\hline Pulmonary valve replacement & $315(36 \%)$ & $15(47 \%)$ & $300(36 \%)$ & 0.20 \\
\hline Other cardiac procedure(s) (eg, branch PA plasty) & $665(76 \%)$ & $30(94 \%)$ & $635(76 \%)$ & 0.02 \\
\hline
\end{tabular}

multivariable analysis of patients who experienced cardiac death or sustained VT (excluding those with non-cardiac and unknown causes) found the same variables to be associated with the primary outcome with a similar c-index of 0.826 as compared with 0.832 for all outcomes. Similar findings were also noted when the analysis was repeated in patients that experienced cardiac death, excluding the four patients with sustained VT.

\section{Subgroup analyses}

To determine whether risk factors for the outcome are the same in patients with and without RV-PA conduits placed as part of TOF repair, we performed additional subgroup analyses (table 4). Multivariable Cox regression analysis showed that the same risk factors that were identified in the entire cohort were also predictive in the 724 patients with no conduit. In contrast, among the 149 patients with RV-PA conduit, predictors of outcome included RV mass-to-volume ratio $\geq 0.5 \mathrm{~g} / \mathrm{mL}$ and $\mathrm{LV}$ end-systolic volume index $\geq 35 \mathrm{~mL} / \mathrm{m}^{2}$.

We further analysed interactions between Doppler-derived RV pressure, RV hypertrophy and clinical outcomes among the 315 patients in whom all of these parameters were available. The group with RV pressure data differed from those without this information $(n=558)$ with regard to demographics, clinical and surgical histories, ECG, exercise and CMR parameters (see online supplementary table $1 S$ ). Of the 302 patients with Doppler data in the RV outflow tract, 29 (10\%) had a peak gradient $\geq 50 \mathrm{~mm} \mathrm{Hg}, 101$ (33\%) had a peak gradient between 20 and $49 \mathrm{~mm} \mathrm{Hg}$, and 172 (57\%) had a peak gradient $<20 \mathrm{~mm} \mathrm{Hg}$. As expected, RV pressure positively correlated with RV mass index $\left(\mathrm{r}_{\mathrm{s}}=0.33, \mathrm{p}<0.001\right)$ and with RV mass-to-volume ratio $\left(\mathrm{r}_{\mathrm{s}}=0.57, \mathrm{p}<0.001\right)$. Compared with the 293 patients who did not have the outcome, those who experienced death or sustained VT $(n=22)$ had a significantly higher RV systolic pressure $(64 \pm 27 \mathrm{~mm} \mathrm{Hg}$ vs $40 \pm 18 \mathrm{~mm} \mathrm{Hg}$, $\mathrm{p}<0.001)$. Multivariable analysis showed that in addition to lower LV EF z score, both RV mass z score (HR 1.08 for every 1 SD increase; 95\% CI 1.02 to $1.14 ; \mathrm{p}=0.008)$ and RV pressure (HR 1.39 for every $10 \mathrm{~mm} \mathrm{Hg}$ increase; 95\% CI 1.19 to 1.62 ; $\mathrm{p}<0.001$ ) were predictive of the outcome (table 4).

\section{DISCUSSION}

This large multicentre observational cohort study identified RV hypertrophy, left or RV systolic dysfunction and atrial tachyarrhythmias as predictors of death or sustained VT in young adult patients with repaired TOF. Moreover, we found that patients with two or three concurrent risk factors were at a much greater risk for poor clinical outcome as compared with those having none or a single risk factor. Subgroup analyses showed that patients with a conduit between the RV and the pulmonary arteries have different risk factors than those without a conduit. In selected patients with noninvasive data on RV pressure, both RV hypertension and increased RV mass are independently associated with poor outcomes despite correlations between these variables. Also notable is the lack of association between RV volumes and the study's primary outcome. It is important to note that in contrast to prior studies that focused on RV volumes, ${ }^{11-13}$ our study is the first to examine the relationships between CMR and other clinical and laboratory parameters and hard clinical outcomes as opposed to surrogate outcomes.

In this study, we chose all-cause mortality or sustained VT as the composite primary outcome because of their clinical 
Table 2 Arrhythmia, exercise, and CMR data

\begin{tabular}{|c|c|c|c|c|}
\hline Arrhythmia data & All patients $(\mathrm{N}=873)$ & Outcome (death/VT) (N=32) & No outcome $(\mathrm{N}=841)$ & $p$ Value \\
\hline QRS duration (ms) & $146 \pm 28(72-226)$ & $154 \pm 32(86-208)$ & $145 \pm 28(72-226)$ & 0.08 \\
\hline Atrial flutter & $60(7 \%)$ & $5(16 \%)$ & $55(7 \%)$ & 0.06 \\
\hline Atrial fibrillation & $37(4 \%)$ & $10(31 \%)$ & $27(3 \%)$ & $<0.001$ \\
\hline Non-sustained ventricular tachycardia & $81(9 \%)$ & $10(31 \%)$ & $71(8 \%)$ & $<0.001$ \\
\hline Prior ablation & $48(5 \%)$ & $4(13 \%)$ & $44(5 \%)$ & 0.09 \\
\hline Permanent pacemaker & $13(1 \%)$ & $0(0 \%)$ & $13(2 \%)$ & 1.00 \\
\hline Implantable defibrillator & $45(5 \%)$ & $7(22 \%)$ & $38(5 \%)$ & $<0.001$ \\
\hline Exercise data & All patients $(\mathrm{N}=551)$ & Outcome (death/VT) (N=11) & No outcome $(N=540)$ & $p$ Value \\
\hline Peak oxygen consumption (mL/kg/min) & $25(2-53)$ & $14(8-27)$ & $25(2-53)$ & 0.001 \\
\hline Percent predicted peak oxygen consumption & $64(18-160)$ & $46(21-77)$ & $64(18-160)$ & 0.003 \\
\hline Ventilatory anaerobic threshold (mL/kg/min) & $15(6-44)$ & $11(7-15)$ & $15(6-44)$ & 0.004 \\
\hline Percent predicted ventilatory anaerobic threshold & $41(22-79)$ & $36(29-49)$ & $41(22-79)$ & 0.12 \\
\hline CMR data & All patients $(\mathrm{N}=873)$ & Outcome (death/VT) (N=32) & No outcome $(\mathrm{N}=841)$ & $p$ Value \\
\hline RV end-diastolic volume index $\left(\mathrm{mL} / \mathrm{m}^{2}\right)$ & $152 \pm 49$ & $145 \pm 42$ & $153 \pm 50$ & 0.34 \\
\hline RV end-systolic volume index $\left(\mathrm{mL} / \mathrm{m}^{2}\right)$ & $79 \pm 35$ & $87 \pm 37$ & $79 \pm 35$ & 0.25 \\
\hline RV EF $(\%)$ & $49 \pm 9$ & $43 \pm 11$ & $49 \pm 9$ & 0.004 \\
\hline RV EF z score & $-1.9 \pm 2.0$ & $-3.2 \pm 2.4$ & $-1.9 \pm 2.0$ & 0.005 \\
\hline $\mathrm{RV}$ mass index $\left(\mathrm{g} / \mathrm{m}^{2}\right)$ & $36 \pm 16$ & $58 \pm 32$ & $35 \pm 14$ & 0.001 \\
\hline RV mass z score & $3.6 \pm 3.0$ & $7.6 \pm 5.8$ & $3.4 \pm 2.7$ & $<0.001$ \\
\hline RV mass/volume ( $\mathrm{g} / \mathrm{mL})$ & $0.24 \pm 0.1$ & $0.42 \pm 0.2$ & $0.24 \pm 0.1$ & $<0.001$ \\
\hline Pulmonary regurgitation (\%) & $35 \pm 17$ & $32 \pm 16$ & $35 \pm 17$ & 0.34 \\
\hline LV end-diastolic volume index $\left(\mathrm{mL} / \mathrm{m}^{2}\right)$ & $86 \pm 22$ & $89 \pm 38$ & $86 \pm 21$ & 0.64 \\
\hline $\mathrm{LV}$ end-systolic volume index $\left(\mathrm{mL} / \mathrm{m}^{2}\right)$ & $37 \pm 15$ & $44 \pm 26$ & $36 \pm 14$ & 0.12 \\
\hline LV EF (\%) & $58 \pm 8$ & $53 \pm 10$ & $58 \pm 8$ & 0.01 \\
\hline LV EF z score & $-1.34 \pm 1.6$ & $-2.57 \pm 2.2$ & $-1.29 \pm 1.6$ & 0.004 \\
\hline $\mathrm{LV}$ mass index $\left(\mathrm{g} / \mathrm{m}^{2}\right)$ & $53 \pm 19$ & $81 \pm 53$ & $52 \pm 16$ & 0.008 \\
\hline LV mass/volume $(\mathrm{g} / \mathrm{mL})$ & $0.63 \pm 0.2$ & $0.90 \pm 0.4$ & $0.62 \pm 0.2$ & 0.002 \\
\hline RV/LV end-diastolic volume ratio & $1.84 \pm 0.61$ & $1.75 \pm 0.61$ & $1.84 \pm 0.61$ & 0.41 \\
\hline
\end{tabular}

QRS duration and CMR data are presented as mean \pm SD (range). Exercise data are presented as median (range).

CMR, cardiac MR; VT, ventricular tachycardia.

importance. Although half of the deaths in this cohort were classified as other or unknown, all-cause mortality is a key

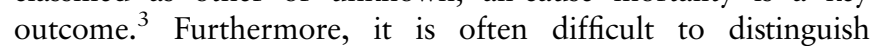
between cardiac and non-cardiac death as comorbidities can be induced or exacerbated by poor cardiac status. Our observation that approximately half of the deaths were classified as other or unknown is similar to the findings of Chiu et $a l^{3}$ that 14 of their 29 patients (48\%) with repaired TOF died of non-cardiac causes. Importantly, we found that the risk factors identified in this study applied to patients regardless of the type of death. Specifically, the same risk factors were associated with the primary outcome when the analysis was restricted only to those patients who experienced cardiac-related death or sustained VT.

Previous studies on risk factors for adverse clinical outcomes late after TOF repair have identified numerous predictors, which can be divided into three broad categories: (1) patient history (eg, older age at repair); (2) electrophysiologic markers (eg, prolonged QRS duration); and (3) hemodynamic abnormalities resulting from severe chronic pulmonary regurgitation and other sequelae of TOF surgery (eg, ventricular dysfunction). ${ }^{6} 71617$ Although these studies provided useful insights into risk stratification, most were constrained by relatively small sample sizes, reliance on surrogate outcomes, or lack of accurate tools to evaluate RV size and function. ${ }^{12} 1^{13-20}$ The importance of our study is underscored by its analysis of data from a large multicentre cohort with clinically important outcomes and its comprehensive collection of variables from all three broad categories. Whereas univariable analysis confirmed several previously noted associations between clinical and laboratory parameters and adverse patient outcomes, multivariable analyses provided new insights.

This study is the first to identify RV hypertrophy as an independent risk factor for death and sustained VT in patients with repaired TOF. Specifically, patients with RV mass-to-volume ratio $\geq 0.3$ were more than five times more likely to experience the outcome as compared with those with a lower ratio. Similar findings were noted with other measures of RV hypertrophy such as mass index and $\mathrm{z}$ score. To our knowledge, only one previous study identified RV hypertrophy as a risk factor for adverse clinical outcomes in this patient population. ${ }^{12}$ Indeed, most studies on the subject, including those with CMR data, have not measured RV mass. ${ }^{11} 1819$ In contrast to patients with congenital heart disease, a large body of literature documents the strongly negative prognostic value of LV hypertrophy in acquired conditions such as essential hypertension and diabetes. ${ }^{21-23}$ Moreover, a recent study showed that increased RV mass was associated with more than twice the risk of heart failure or death in adult patients enrolled in the Multi-Ethnic Study of Atherosclerosis (MESA). ${ }^{24}$ Based on studies of the myocardium in these and other acquired cardiovascular diseases, it is reasonable to suspect that the increase in RV mass is due not only to increase in myocyte volume but also due to increase in interstitial volume with increased collagen concentration and 
Table 3 Univariable predictors of outcome

\begin{tabular}{|c|c|c|c|c|c|}
\hline & & HR & $95 \% \mathrm{Cl}$ & $\mathrm{p}$ Value & C Index \\
\hline \multicolumn{6}{|l|}{ Demographics and clinical variables } \\
\hline Gender, male & & 1.49 & (0.72 to 3.05$)$ & 0.28 & 0.596 \\
\hline Body mass index $\geq 30\left(\mathrm{~kg} / \mathrm{m}^{2}\right)$ & & 1.89 & (0.84 to 4.26$)$ & 0.12 & 0.556 \\
\hline Age at repair $\geq 7$ years & & 2.51 & (1.25 to 5.05$)$ & 0.01 & 0.596 \\
\hline Age at $C M R \geq 50$ years & & 3.96 & (1.77 to 8.83$)$ & 0.001 & 0.579 \\
\hline TOF with pulmonary atresia & & 3.34 & (1.63 to 6.83$)$ & 0.001 & 0.636 \\
\hline Prior systemic-pulmonary artery shunt & & 2.40 & (1.18 to 4.86$)$ & 0.02 & 0.618 \\
\hline RV-to-PA conduit & & 3.68 & (1.80 to 7.49$)$ & $<0.001$ & 0.634 \\
\hline Atrial arrhythmia* & & 4.52 & (2.24 to 9.13 ) & $<0.001$ & 0.643 \\
\hline Ventricular arrhythmiat & & 2.23 & (1.08 to 4.57$)$ & 0.03 & 0.566 \\
\hline \multicolumn{6}{|l|}{ ECG variables } \\
\hline QRS duration (ms) & $\uparrow 10$ & 1.11 & (0.97 to 1.27$)$ & 0.12 & 0.578 \\
\hline QRS duration $\geq 180$ (ms) & & 3.17 & (1.42 to 7.10$)$ & 0.005 & 0.586 \\
\hline \multicolumn{6}{|l|}{ Exercise variables } \\
\hline Percent predicted peak work rate & $\downarrow 5$ & 1.28 & (1.05 to 1.56$)$ & 0.02 & 0.735 \\
\hline Percent predicted peak $\mathrm{VO}_{2}$ & $\downarrow 5$ & 1.20 & (1.01 to 1.43$)$ & 0.03 & 0.725 \\
\hline Percent predicted VAT & $\downarrow 5$ & 1.37 & (0.81 to 2.31$)$ & 0.25 & 0.735 \\
\hline \multicolumn{6}{|l|}{ CMR variables } \\
\hline RV end-diastolic volume index $\left(\mathrm{mL} / \mathrm{m}^{2}\right)$ & $\uparrow 5$ & 1.00 & (0.96 to 1.03$)$ & 0.77 & 0.500 \\
\hline RV end-systolic volume index, $\mathrm{mL} / \mathrm{m}^{2}$ ) & $\uparrow 5$ & 1.03 & (0.99 to 1.07$)$ & 0.15 & 0.609 \\
\hline RV EF (\%) & $\downarrow 5$ & 1.36 & (1.14 to 1.61$)$ & $<0.001$ & 0.710 \\
\hline RV mass index $\left(\mathrm{g} / \mathrm{m}^{2}\right)$ & $\uparrow 10$ & 1.25 & (1.14 to 1.36$)$ & $<0.001$ & 0.758 \\
\hline RV mass z score & $\uparrow 1$ & 1.12 & (1.07 to 1.17$)$ & $<0.001$ & 0.769 \\
\hline RV mass/volume ( $\mathrm{g} / \mathrm{mL})$ & $\uparrow 0.1$ & 1.50 & (1.29 to 1.75$)$ & $<0.001$ & 0.774 \\
\hline Pulmonary regurgitation (\%) & $\uparrow 5$ & 0.96 & (0.86 to 1.08$)$ & 0.48 & 0.516 \\
\hline LV end-diastolic volume index $\left(\mathrm{mL} / \mathrm{m}^{2}\right)$ & $\uparrow 5$ & 1.06 & (0.98 to 1.13$)$ & 0.13 & 0.522 \\
\hline LV end-systolic volume index $\left(\mathrm{mL} / \mathrm{m}^{2}\right)$ & $\uparrow 5$ & 1.15 & (1.07 to 1.24$)$ & $<0.001$ & 0.650 \\
\hline LV EF (\%) & $\downarrow 5$ & 1.40 & (1.15 to 1.70$)$ & 0.001 & 0.697 \\
\hline $\mathrm{LV}$ mass index $\left(\mathrm{g} / \mathrm{m}^{2}\right)$ & $\uparrow 10$ & 1.28 & (1.19 to 1.39$)$ & $<0.001$ & 0.749 \\
\hline LV mass/volume ( $\mathrm{g} / \mathrm{mL})$ & $\uparrow 0.1$ & 1.16 & (1.07 to 1.27 ) & $<0.001$ & 0.765 \\
\hline RV/LV end-diastolic volume ratio & $\downarrow 1$ & 1.32 & (0.71 to 2.45 ) & 0.39 & 0.575 \\
\hline
\end{tabular}

*Defined as atrial flutter, atrial fibrillation, or supraventricular tachycardia.

tDefined $>20$ couplets or $>100$ isolated premature ventricular complexes in a 24-h period, or nonsustained VT.

CMR, cardiac MR; PA, pulmonary artery; TOF, tetralogy of Fallot; VAT, ventilatory aerobic threshold; VT, ventricular tachycardia.

Table 4 Multivariable predictors of outcome

\begin{tabular}{|c|c|c|c|c|c|}
\hline & HR & $95 \% \mathrm{Cl}$ & $\mathrm{p}$ Value & C index & $R^{2}$ \\
\hline \multicolumn{6}{|l|}{ All subjects ( $N=873 ; 32$ outcomes) } \\
\hline \multicolumn{6}{|l|}{ Model 1} \\
\hline RV mass/volume ratio $\geq 0.30(\mathrm{~g} / \mathrm{mL})$ & 5.04 & (2.30 to 11.0$)$ & $<0.001$ & 0.832 & 0.246 \\
\hline LV EF z score $<-2.0$ & 3.34 & (1.59 to 7.01$)$ & 0.001 & & \\
\hline History of atrial arrhythmia & 3.65 & (1.75 to 7.62$)$ & 0.001 & & \\
\hline \multicolumn{6}{|l|}{ Model 2} \\
\hline RV mass/volume ratio $\geq 0.30(\mathrm{~g} / \mathrm{mL})$ & 4.17 & (1.96 to 8.86$)$ & $<0.001$ & 0.781 & 0.215 \\
\hline RV EF z score $<-2.0$ & 2.59 & (1.19 to 5.64$)$ & 0.02 & & \\
\hline History of atrial arrhythmia & 3.61 & (1.77 to 7.34$)$ & $<0.001$ & & \\
\hline \multicolumn{6}{|c|}{ Subjects without RV-PA conduits ( $N=724 ; 19$ outcomes) } \\
\hline RV mass/volume ratio $\geq 0.30(\mathrm{~g} / \mathrm{mL})$ & 5.58 & (1.99 to 15.7$)$ & 0.001 & 0.848 & 0.278 \\
\hline LV EF z score $<-2.0$ & 5.48 & (1.96 to 15.4$)$ & 0.001 & & \\
\hline History of atrial arrhythmia & 6.14 & (2.36 to 16.0$)$ & $<0.001$ & & \\
\hline \multicolumn{6}{|c|}{ Subjects with RV-PA conduits ( $N=149 ; 13$ outcomes) } \\
\hline RV mass/volume ratio $\geq 0.50(\mathrm{~g} / \mathrm{mL})$ & 9.31 & (2.74 to 31.6$)$ & $<0.001$ & 0.799 & 0.292 \\
\hline LV end-systolic volume index $\geq 35\left(\mathrm{~mL} / \mathrm{m}^{2}\right)$ & 5.79 & (1.50 to 22.3$)$ & 0.01 & & \\
\hline \multicolumn{6}{|l|}{ Subjects with Doppler data ( $\mathrm{N}=315 ; 22$ outcomes) } \\
\hline RV mass z score $(\uparrow 1)$ & 1.08 & (1.02 to 1.14$)$ & 0.008 & 0.864 & 0.362 \\
\hline LV EF z score ( $\downarrow 1)$ & 1.52 & (1.19 to 1.94$)$ & 0.001 & & \\
\hline RV pressure by Doppler ( $\uparrow 10 \mathrm{~mm} \mathrm{Hg})$ & 1.39 & (1.19 to 1.62$)$ & $<0.001$ & & \\
\hline
\end{tabular}

$\mathrm{PA}$, pulmonary artery. 
Figure 1 Kaplan-Meier curves for the outcome ( death and sustained VT) according to risk factors. Access the article online to view this figure in colour.

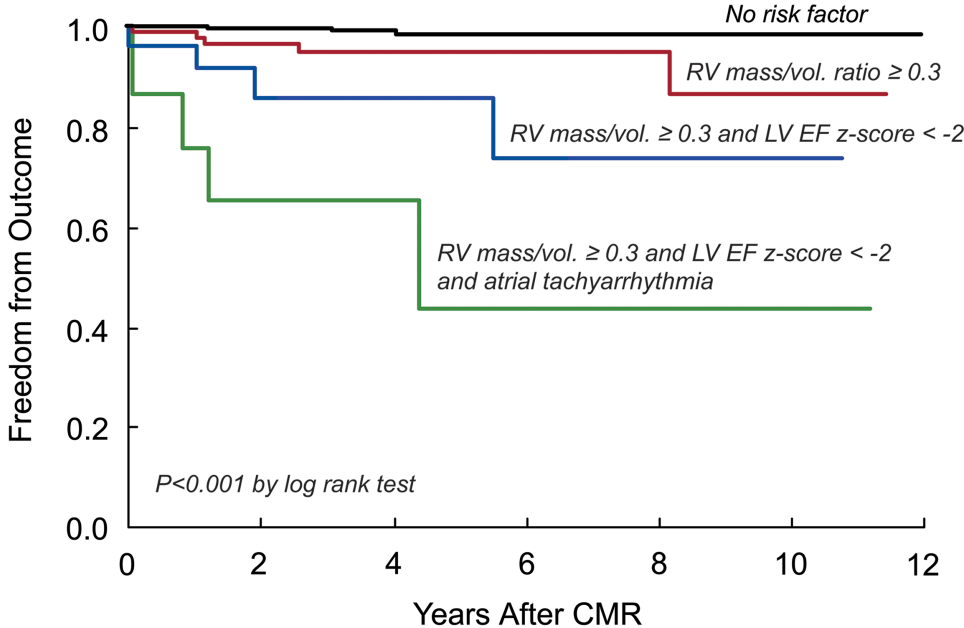

No. at Risk: No risk factors 435 RV mass/vol. $\geq 0.3 \quad 96$ RV mass/Vol. $\geq 0.3$

+ LVEF $z<-2$

All three factors

249
69
16
6

\section{2}

29

$\begin{array}{rr}2 & 1 \\ 13 & 7 \\ 6 & 3 \\ 1 & 1\end{array}$

gross fibrosis. ${ }^{25}$ If confirmed, this may be a target for future therapies.

To further explore whether RV hypertrophy is a surrogate of RV hypertension and to determine which parameter better predicts the clinical outcome, we explored these questions in a subgroup of patients with Doppler estimation of RV systolic pressure. As expected, the two variables correlated with each other. Unexpectedly, however, both were associated with the outcome in multivariable analysis. These results suggest that despite a moderate correlation between higher pressure and increased mass, each parameter contributes to risk through different mechanisms or that they synergistically interact via a common pathway. We speculate that the RV hypertrophy observed in our study results from a maladaptive process in response to prolonged volume and/or pressure overload leading to pathological increase in the ratio of interstitial content (primarily collagen and fibroblasts) to myocytes volume. Such maladaptive pathological process has been shown in a variety of diseases affecting the $\mathrm{LV}^{26}$ Additional factors such as intraventricular and interventricular dyssynchrony may also contribute to mechanical inefficiency of ventricular function and pathological hypertrophy.

From a practical perspective, the findings of our study provide a framework for risk stratification of patients with repaired TOF. It remains speculative whether therapeutic interventions designed to prevent or lessen the risk factors identified in this cohort will lead to improved clinical outcomes, including longer life expectancy and freedom from major arrhythmias. Possible therapeutic interventions include surgical or transcatheter pulmonary valve implantation prior to development of ventricular dysfunction, development of RV hypertrophy or onset of atrial tachyarrhythmias; ablation or other therapies for atrial flutter or fibrillation; early intervention to decrease RV systolic pressure (eg, catheter or surgical treatment of pulmonary artery stenosis); and, finally, pharmacological therapy designed to decrease diffuse myocardial fibrosis.

Our study has several limitations. The cohort is restricted to subjects who have undergone CMR; this limitation is partially mitigated by the routine use of CMR in this patient group at the participating centres. In addition, patients with pacemakers or defibrillators implanted before CMR were excluded. Although we made every effort to ascertain clinical outcomes through regular updates of the registry every 6 months and review of national death registries, it is conceivable that some outcomes were not recorded. Finally, the cutoff values for RV mass-to-volume ratio reported here might not be generalisable as measurement of RV mass may vary by technique.

In conclusion, RV hypertrophy and LV and RV dysfunction measured by CMR, as well as atrial tachyarrhythmias predict death and sustained VT in patients with repaired TOF. The likelihood of a poor outcome increases substantially when multiple risk factors coexist. Elevated RV systolic pressure may confer an additional risk, though the mechanism that distinguishes it from that of RV hypertrophy requires additional study. These findings may inform the design of future trials on therapeutic interventions in this population.

\section{Key messages}

What is already known about this subject?

Patients with repaired tetralogy of Fallot (TOF) experience increased rates of mortality and morbidity beginning in early adulthood but the risk factors for late adverse outcomes are poorly defined.

How might this impact on clinical practice?

Our findings inform risk stratification and clinical decisions as well as the design of future trials on therapeutic interventions in patients with repaired TOF.

\section{What this study adds?}

We analysed risk factors for adverse clinical outcomes in a large, contemporarily managed cohort of young adult patients with repaired TOF enrolled in the International Multicentre TOF Registry (INdiCaTOR). The results uncover new risk factors for death and sustained ventricular tachycardia, including right ventricular hypertrophy, left and/or right ventricular dysfunction and history of atrial tachyarrhythmias. This information informs risk stratification and clinical decisions in this rapidly growing population of adult patients. 
Acknowledgements We thank Sarah P Evans, BS, and loannis Germanakis, MD for their assistance with data processing. The views expressed in this publication are those of the author(s) and not necessarily those of the NHS, the National Institute for Health Research or the Department of Health.

Contributors AMV: conceived and designed the research, acquired the data, analysed and interpreted the data, drafted the manuscript and approved the final version of the manuscript. GEA: analyzed and interpreted the data, contributed to drafting the manuscript, critically reviewed the manuscript and approved the final version of the manuscript. JS: acquired the data, analysed and interpreted the data, contributed to drafting the manuscript, critically reviewed the manuscript and approved the final version of the manuscript. KG: performed statistical analysis, analysed and interpreted the data, drafted part of the manuscript, critically reviewed the manuscript and approved the final version of the manuscript. RI, ZK: acquired data, critically reviewed the manuscript and approved the final version of the manuscript. MAG, PJK, MJL, BM, AJP, RW, SVB-N, MG: contributed to the study design, contributed to acquisition of data, critically reviewed the manuscript and approved the final version of the manuscript. TG: responsible for all aspects of the research, conceived and designed the research, analysed and interpreted the data, drafted the manuscript and approved the final version of the manuscript.

Funding Higgins Family Noninvasive Research Fund at Boston Children's Hospita (TG, AMV, AJP), the Dunlevie Foundation (AMV, JS, MJL, GEA), the Lerner Research award (AMV), NIH/NHLBI 1 R01 HL089269-01A2 (TG), and the British Heart Foundation Fellowship award (SVB-N). SVB-N, MAG and PJK were supported by the NIHR Cardiovascular Biomedical Research Unit of Royal Brompton and Harefield NHS Foundation Trust and Imperial College London. This report is independent research by the National Institute for Health Research Biomedical Research Unit Funding Scheme.

\section{Competing interests None.}

Ethics approval Institutional Review Board.

Provenance and peer review Not commissioned; externally peer reviewed.

Open Access This is an Open Access article distributed in accordance with the Creative Commons Attribution Non Commercial (CC BY-NC 3.0) license, which permits others to distribute, remix, adapt, build upon this work non-commercially, and license their derivative works on different terms, provided the original work is properly cited and the use is non-commercial. See: http://creativecommons.org/ licenses/by-nc/3.0/

\section{REFERENCES}

1 Nollert G, Fischlein T, Bouterwek $\mathrm{S}$, et al. Long-term results of total repair of tetralogy of Fallot in adulthood: 35 years follow-up in 104 patients corrected at the age of 18 or older. Thorac Cardiovasc Surg 1997;45:178-81.

2 Murphy JG, Gersh BJ, Mair DD, et al. Long-term outcome in patients undergoing surgical repair of tetralogy of Fallot. N Engl J Med 1993;329:593-9.

3 Chiu SN, Wang JK, Chen HC, et al. Long-term survival and unnatural deaths of patients with repaired tetralogy of Fallot in an Asian cohort. Circ Cardiovasc Qual Outcomes 2012:5:120-5.

4 Hickey EJ, Veldtman G, Bradley TJ, et al. Late risk of outcomes for adults with repaired tetralogy of Fallot from an inception cohort spanning four decades. Eur $J$ Cardiothorac Surg 2009;35:156-64; discussion 64

5 Khairy $\mathrm{P}$, Dore $\mathrm{A}$, Poirier $\mathrm{N}$, et al. Risk stratification in surgically repaired tetralogy of Fallot. Expert Rev Cardiovasc Ther 2009;7:755-62.

6 Gatzoulis MA, Balaji S, Webber SA, et al. Risk factors for arrhythmia and sudden cardiac death late after repair of tetralogy of Fallot: a multicentre study. Lancet 2000;356:975-81.

7 Ghai A, Silversides C, Harris L, et al. Left ventricular dysfunction is a risk factor for sudden cardiac death in adults late after repair of tetralogy of Fallot. I Am Coll Cardiol 2002:40:1675-80
8 Gatzoulis MA, Clark AL, Cullen S, et al. Right ventricular diastolic function 15 to 35 years after repair of tetralogy of Fallot. Restrictive physiology predicts superior exercise performance. Circulation 1995:91:1775-81.

9 Mooij CF, de Wit CJ, Graham DA, et al. Reproducibility of MRI measurements of right ventricular size and function in patients with normal and dilated ventricles. J Magn Reson Imaging 2008;28:67-73.

10 Geva T. Repaired tetralogy of Fallot: the roles of cardiovascular magnetic resonance in evaluating pathophysiology and for pulmonary valve replacement decision support. J Cardiovasc Magn Reson 2011;13:9.

11 Davlouros PA, Kilner PJ, Hornung TS, et al. Right ventricular function in adults with repaired tetralogy of Fallot assessed with cardiovascular magnetic resonance imaging: detrimental role of right ventricular outflow aneurysms or akinesia and adverse right-to-left ventricular interaction. J Am Coll Cardiol 2002:40:2044-52.

12 Geva T, Sandweiss BM, Gauvreau K, et al. Factors associated with impaired clinical status in long-term survivors of tetralogy of Fallot repair evaluated by magnetic resonance imaging. J Am Coll Cardiol 2004;43:1068-74.

13 Knauth AL, Gauvreau K, Powell AJ, et al. Ventricular size and function assessed by cardiac MRI predict major adverse clinical outcomes late after tetralogy of Fallot repair. Heart 2008;94:211-16.

14 Valente AM, Gauvreau K, Assenza GE, et al. Rationale and design of an International Multicenter Registry of patients with repaired tetralogy of Fallot to define risk factors for late adverse outcomes: the INDICATOR cohort. Pediatr Cardiol 2013;34:95-104.

15 Kilner PJ, Geva T, Kaemmerer $\mathrm{H}$, et al. Recommendations for cardiovascular magnetic resonance in adults with congenital heart disease from the respective working groups of the European Society of Cardiology. Eur Heart 2010:31:794-805.

16 Khairy P, Landzberg MJ, Gatzoulis MA, et al. Value of programmed ventricular stimulation after tetralogy of fallot repair: a multicenter study. Circulation 2004; 109:1994-2000

17 Harrison DA, Harris L, Siu SC, et al. Sustained ventricular tachycardia in adult patients late after repair of tetralogy of Fallot. J Am Coll Cardiol 1997;30:1368-73.

18 Babu-Narayan SV, Kilner PJ, Li W, et al. Ventricular fibrosis suggested by cardiovascular magnetic resonance in adults with repaired tetralogy of fallot and its relationship to adverse markers of clinical outcome. Circulation 2006;113:405-13.

19 Lu JC, Cotts TB, Agarwal PP, et al. Relation of right ventricular dilation, age of repair, and restrictive right ventricular physiology with patient-reported quality of life in adolescents and adults with repaired tetralogy of fallot. Am J Cardiol 2010;106:1798-802.

20 Wald RM, Haber I, Wald R, et al. Effects of regional dysfunction and late gadolinium enhancement on global right ventricular function and exercise capacity in patients with repaired tetralogy of Fallot. Circulation 2009;119:1370-7.

21 Jain A, Tandri H, Dalal D, et al. Diagnostic and prognostic utility of electrocardiography for left ventricular hypertrophy defined by magnetic resonance imaging in relationship to ethnicity: the Multi-Ethnic Study of Atherosclerosis (MESA). Am Heart J 2010;159:652-8.

22 Levy D, Garrison RJ, Savage DD, et al. Prognostic implications of echocardiographically determined left ventricular mass in the Framingham Heart Study. N Engl J Med 1990;322:1561-6.

23 Benjamin EJ, Levy D. Why is left ventricular hypertrophy so predictive of morbidity and mortality? Am J Med Sci 1999;317:168-75.

24 Kawut SM, Barr RG, Lima JA, et al. Right Ventricular Structure Is Associated With the Risk of Heart Failure and Cardiovascular Death: The Multi-Ethnic Study of Atherosclerosis (MESA)-Right Ventricle Study. Circulation 2012;126:1681-8.

25 Kret M, Arora R. Pathophysiological basis of right ventricular remodeling. J Cardiovasc Pharmacol Ther 2007;12:5-14.

26 Mewton N, Liu CY, Croisille P, et al. Assessment of myocardial fibrosis with cardiovascular magnetic resonance. J Am Coll Cardiol 2011;57:891-903. 